\section{(6) OPEN ACCESS}

\title{
Vitamin D status of early preterm infants and the effects of vitamin D intake during hospital stay
}

\author{
Nagendra Monangi, ${ }^{1}$ Jonathan L Slaughter, ${ }^{2,3}$ Adekunle Dawodu, ${ }^{4}$ Carrie Smith, ${ }^{5}$ \\ Henry T Akinbi ${ }^{1}$
}

${ }^{1}$ Neonatal Perinatal Medicine, Perinatal Institute, Cincinnati Children's Hospital Medical

Center/University of Cincinnati, Cincinnati, Ohio, USA

${ }^{2}$ Center for Perinatal Research and Ohio Perinatal Research

Network, Nationwide

Children's Hospital, Columbus, Ohio, USA

${ }^{3}$ Department of Pediatrics, The Ohio State University,

Columbus, Ohio, USA

${ }^{4}$ Global Health Center

Cincinnati Children's Hospital Medical Center/University of Cincinnati, Cincinnati, Ohio, USA

${ }^{5}$ University of Cincinnati Medical Center, Cincinnati, Ohio, USA

\section{Correspondence to}

Dr Henry T Akinbi, Division of Neonatology and Pulmonary Biology, 3333 Burnet Ave, Cincinnati, OH 45229-3039, USA; henry.akinbi@cchmc.org

NM and JLS contributed equally.

Received 5 March 2013 Revised 24 June 2013 Accepted 25 June 2013 Published Online First 13 July 2013

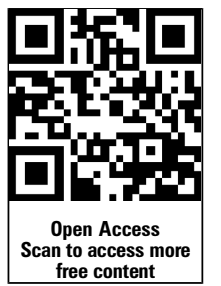

To cite: Monangi $\mathrm{N}$, Slaughter JL, Dawodu A, et al. Arch Dis Child Fetal Neonatal Ed 2014:99: F166-F168.

\section{ABSTRACT}

Objectives To evaluate vitamin D (vitD) status in early preterm infants (EPTIS) at birth and during birth

hospitalisation on current vitD intake.

Design/methods Serum 25-hydroxyvitamin-D [25(OH) D] concentrations, vitD intake and risk factors for low vitD status were assessed in 120 infants born at $\leq 32$ weeks gestation.

Results Mean (SD) serum 25(OH)D at birth was 46.2 (14.0) $\mathrm{nmol} / \mathrm{L}$ with lower concentrations in infants born $<28$ weeks than at $28-32$ weeks gestation, $p=0.02$. Serum $25(\mathrm{OH}) \mathrm{D}$ was $<50 \mathrm{nmol} / \mathrm{L}$ in $63 \%$ of mothers, $64 \%$ of infants at birth and $35 \%$ of infants at discharge. Mean daily vitD intake was $289 \pm 96 \mathrm{IU}$ at 4 weeks of age and $60 \%$ achieved $400 \mathrm{lU} /$ day intake at discharge.

Conclusions Serum $25(\mathrm{OH}) \mathrm{D}<50 \mathrm{nmol} / \mathrm{L}$ was widespread in parturient women and in EPTIs at birth and at discharge. Optimising maternal vitD status during pregnancy and improving postnatal vitD intake may enhance infant vitD status during hospitalisation.

\section{INTRODUCTION}

Low vitamin D (vitD) status is a risk factor for rickets and has been associated with increased prevalence of respiratory infections and other adverse health outcomes in infants and children. ${ }^{12}$ In response to the concern about widespread childhood vitD deficiency, professional bodies have recommended vitD intake of $400 \mathrm{IU} /$ day for all infants. $^{1}{ }^{3}$ The European Society for Paediatrics Gastroenterology, Hepatology and Nutrition recommends 800-1000 IU/day for preterm infants. ${ }^{4}$ Based on biomarkers of vitD status mostly in adults, serum 25-hydroxyvitamin-D [25(OH)D] concentration $\geq 50 \mathrm{nmol} / \mathrm{L}$ was also recommended. ${ }^{13}$ However, the functional benefit of this level is controversial. Early preterm infants (EPTIs) are likely at risk of low vitD status because of high prevalence of vitD deficiency in pregnancy, ${ }^{5}$ lack of sunlight exposure during hospitalisation and difficulty in ensuring adequate enteral nutrition. We hypothesised that serum $25(\mathrm{OH}) \mathrm{D}$ concentrations would be low at birth in EPTIs ( $<32$ weeks postmenstrual age (PMA)) and that current vitD intake during hospitalisation would be insufficient to achieve a serum $25(\mathrm{OH}) \mathrm{D} \geq 50 \mathrm{nmol} / \mathrm{L}$ at discharge. We assessed the serum $25(\mathrm{OH}) \mathrm{D}$ concentrations at birth in EPTIs and the effect of current vitD intake during hospitalisation on vitD status.

\section{MATERIALS AND METHODS}

Infants born at $\leq 32$ weeks PMA admitted to the newborn intensive care units (NICUs) at the University of Cincinnati Medical Center,

\section{What is already known on this topic}

- Vitamin D deficiency is common in infants that do not receive vitD supplements.

- Vitamin D intake of 400 IU/day is recommended for infants to achieve a target serum $25(\mathrm{OH}) \mathrm{D}$ concentrations $\geq 50 \mathrm{nmol} / \mathrm{L}$.

\section{What this study adds}

Low serum concentrations ( $<50 \mathrm{nmol} / \mathrm{L})$ are common in preterm infants during birth hospitalisation and at discharge from the neonatal intensive care unit.

- Current neonatal nutritional strategies for early preterm infants may be insufficient to achieve recommended vitD intake and target serum 25 (OH)D concentrations.

- Improving maternal vitD status during pregnancy and neonatal vitD supplementation is warranted to optimise vitD status of preterm infants in early infancy.

Cincinnati, Ohio, the Ohio State University Medical Center or Nationwide Children's Hospital in Columbus, Ohio from December 2010 to February 2012 were enrolled after parental informed consent. The study was approved by the respective Institutional Review Boards. Infants were excluded for lethal congenital malformations, severe illness at birth deemed incompatible with survival or multiple gestation pregnancies.

\section{Study protocol}

Data collected included maternal sociodemographics, perinatal history, prenatal vitD intake and birth season. Daily vitD intake was estimated at 4 weeks of age from the concentrations in parenteral nutrition $(160 \mathrm{IU} / \mathrm{kg})$, human milk, ${ }^{6}$ human milk fortifier (120 IU vitD per $100 \mathrm{~mL}$ milk), and in formula and $\mathrm{vit}_{3}$ supplements of $200 \mathrm{IU} /$ day from multivitamin D drops from 2 weeks of age.

\section{Vitamin D status during hospitalisation}

Blood specimens were obtained within $48 \mathrm{~h}$ of birth, at 4 weeks of age and at 36 weeks PMA or at discharge. Serum $25(\mathrm{OH}) \mathrm{D}$ concentrations were measured from the dried blood spots using liquid chromatography/tandem mass spectrometry (ZRT 
Table 1 Demographic characteristics and serum 25-hydroxyvitamin-D concentrations

\begin{tabular}{|c|c|c|c|}
\hline Characteristics & All infants $(n=120)$ & Infants born $<28$ weeks PMA ( $n=67)$ & $\begin{array}{l}\text { Infants born between } 28 \\
\text { and } 32 \text { weeks PMA }(n=53)\end{array}$ \\
\hline n (\%) male & $51(43)$ & $27(41)$ & $24(45)$ \\
\hline n (\%) African-American & $46(39)$ & $29(43)$ & $17(32)$ \\
\hline PMA in weeks & $28.1(1.2)$ & $26.4(1.0)$ & $30.4(0.8)$ \\
\hline Birth weight in $\mathrm{g}$ & $1028.1(236.8)$ & $831.5(231.7)$ & $1276.6(245.9)$ \\
\hline Maternal $25(\mathrm{OH}) \mathrm{D}$ in $\mathrm{nmol} / \mathrm{L}$ at delivery & $49.2(19.2)$ & $44.0(12.5)$ & $55.7(22.7)^{*}$ \\
\hline n (\%) mothers with $25(\mathrm{OH}) \mathrm{D}<50 \mathrm{nmol} / \mathrm{L}$ & $75(63)$ & $45(67)$ & $30(57)$ \\
\hline Infant $25(\mathrm{OH}) \mathrm{D}$ in nmol/L at birth & $46.3(14.0)$ & $42.0(9.8)$ & $51.8(19.5)^{* *}$ \\
\hline n (\%) infants with $25(\mathrm{OH}) \mathrm{D}<50 \mathrm{nmol} / \mathrm{L}$ & $76(64)$ & $47(70)$ & $29(55)^{* *}$ \\
\hline $25(\mathrm{OH}) \mathrm{D}$ in nmol/L at 36 weeks PMA or at discharge & $64(21.8)$ & $59.2(20.5)$ & $71(23.5)^{* * *}$ \\
\hline n (\%) infants with $25(\mathrm{OH}) \mathrm{D}<50 \mathrm{nmol} / \mathrm{L}$ at 36 weeks PMA or at discharge & $43(36)$ & $27(40)$ & $16(30)$ \\
\hline
\end{tabular}

laboratories in Beaverton, Oregon). The intra- and inter-assay coefficients of variation were $8.6 \%$ and $11 \%$, respectively.

\section{Statistical analysis}

Data were analysed by PMA ( $<28$ weeks versus $28-32$ weeks) to account for gestational age-associated differences in hospital course. Relationships between variables were tested using Pearson's correlation coefficient. A multivariable logistic regression model with serum $25(\mathrm{OH}) \mathrm{D}$ concentration as an outcome variable was constructed to control for potential confounding variables. $p$ Values of $<0.05$ were considered significant.

\section{RESULTS}

A total of 120 mother/infant pairs were enrolled. Table 1 shows the demographic characteristics and serum $25(\mathrm{OH}) \mathrm{D}$ concentrations. Mean serum 25(OH)D concentration at birth for the EPTI cohort was $46.3 \mathrm{nmol} / \mathrm{L}$ (SD 14.0) with lower concentrations in infants born $<28$ weeks PMA $(42.0 \pm 9.8 \mathrm{nmol} / \mathrm{L})$ than at $28-32$ weeks $(51.8 \pm 19.5 \mathrm{nmol} / \mathrm{L}), \mathrm{p}=0.02$.

Overall, 64\% of infants had serum $25(\mathrm{OH}) \mathrm{D}$ concentrations $<50 \mathrm{nmol} / \mathrm{L}$ at birth. Approximately $70 \%$ of infants born $<28$ weeks and $55 \%$ of infants born between 28 and 32 weeks had serum $25(\mathrm{OH}) \mathrm{D}$ concentrations $<50 \mathrm{nmol} / \mathrm{L}, \mathrm{p}=0.02$. Maternal serum 25(OH)D concentration was $49.0 \pm 21.3 \mathrm{nmol} / \mathrm{L}$. Sixty-three per cent of mothers had $25(\mathrm{OH}) \mathrm{D}$ concentrations $<50 \mathrm{nmol} / \mathrm{L}$. Infant serum $25(\mathrm{OH}) \mathrm{D}$ at birth correlated with maternal 25(OH)D $(\mathrm{r}=0.77, \mathrm{p}=0.001)$ and with infant serum $25(\mathrm{OH}) \mathrm{D}$ at discharge $(\mathrm{r}=0.65, \mathrm{p}=0.04)$.

Following multivariable logistic regression, the factors that were significantly associated with serum $25(\mathrm{OH}) \mathrm{D}<50 \mathrm{nmol} / \mathrm{L}$ were low maternal vitD status (adjusted OR (aOR), 5.2 (95\% CI 2.9 to 9.6$)$ ), African-American ethnicity (3.2 (1.3 to 7.9)), PMA $<28$ weeks (2.6(1.1 to 6.2$)$ ), lack of maternal prenatal vitD use (4.2 (2.1 to 8.5)) and winter birth (4.3 (2.3 to 9.3)), (table 2).

Mean vitD intake at 4 weeks postnatal age was $289 \pm 96 \mathrm{IU} /$ day and was not significantly different in infants born at $<28$ weeks PMA (232 \pm 106 IU) than at $28-32$ weeks PMA (316 $\pm 94 \mathrm{IU}), \mathrm{p}=0.08$. At discharge or 36 weeks PMA, $60 \%$ of the entire cohort of preterm infants attained $400 \mathrm{IU}$ per day.

With the current vitD intake during hospitalisation in the NICUs, $40 \%$ of infants born $<28$ weeks PMA and $30 \%$ of infants born between 28 and 32 weeks had serum $25(\mathrm{OH}) \mathrm{D}$ concentrations $<50 \mathrm{nmol} / \mathrm{L}$ at 36 weeks PMA or at discharge.

\section{DISCUSSION}

In this multicentre study, two-thirds of preterm infants and their mothers had serum $25(\mathrm{OH}) \mathrm{D}$ concentrations $<50 \mathrm{nmol} / \mathrm{L}$, a value considered deficient by some professional bodies. ${ }^{1}$ Interestingly, the odds of a serum $25(\mathrm{OH}) \mathrm{D}$ level $<50 \mathrm{nmol} / \mathrm{L}$ was increased 2.6-fold in infants born $<28$ weeks PMA than at 28-32 weeks. Presumably, the high prevalence of serum 25 $(\mathrm{OH}) \mathrm{D}$ concentrations $<50 \mathrm{nmol} / \mathrm{L}$ at birth in our cohort of

Table 2 Factors associated with infant serum $25(\mathrm{OH}) \mathrm{D}<50 \mathrm{nmol} / \mathrm{L}$ at birth in multivariable analysis

\begin{tabular}{|c|c|c|c|}
\hline Characteristic & Variable & Crude OR $(95 \% \mathrm{CI})$ & aOR $(95 \% \mathrm{Cl})$ \\
\hline Maternal 25-hydroxyvitamin-D (nmol/L) & $\begin{array}{l}\geq 50 \\
<50\end{array}$ & $\begin{array}{l}- \\
5.8 \text { (3.4 to } 9.6)\end{array}$ & $\begin{array}{l}- \\
5.2(2.9 \text { to } 9.6)\end{array}$ \\
\hline Maternal race/ethnicity & $\begin{array}{l}\text { Caucasian/other } \\
\text { African-American }\end{array}$ & 3.4 (1.6 to 8.2$)$ & $3.2(1.3$ to 7.9$)$ \\
\hline Gestational age & $\begin{array}{l}28-32 \text { weeks } \\
<28 \text { weeks }\end{array}$ & - 2.4 (1.3 to 5.9$)$ & $\overline{2.6}(1.1$ to 6.2$)$ \\
\hline Maternal prenatal vitamin use & $\begin{array}{l}\text { No } \\
\text { Yes }\end{array}$ & $\overline{0} .4(0.2$ to 0.7$)$ & $\overline{-} .24$ (0.1 to 0.5$)$ \\
\hline Season of birth & $\begin{array}{l}\text { Summer } \\
\text { Fall } \\
\text { Winter } \\
\text { Spring }\end{array}$ & $\begin{array}{l}- \\
1.8(0.8 \text { to } 3.2) \\
4.7(2.4 \text { to } 9.6) \\
2.3(1.2 \text { to } 4.2)\end{array}$ & $\begin{array}{l}- \\
2.1(1.1 \text { to } 4.2) \\
4.3(2.3 \text { to } 9.3) \\
1.8(0.9 \text { to } 2.8)\end{array}$ \\
\hline
\end{tabular}

All parameter estimates were adjusted for other covariates. Variables entered from univariate analysis that were not statistically significant in multivariable analysis were maternal age, maternal education, insurance and body mass index. 
EPTIs and the higher prevalence in infants born $<28$ weeks than in infants born between 28 and 32 weeks are reflective of maternal vitD status.

Maternal vitD deficiency predisposes to low vitD status in term infants at birth. ${ }^{78}$ Similarly, we found that maternal vitD deficiency predicted low vitD status in EPTIs in agreement with our hypothesis. Our data also suggest that vitD status of EPTIs at birth correlated with the vitD status at discharge, underscoring the importance of optimising the vitD status of infants at birth. As reported in studies in term infants, ${ }^{7} 8$ AfricanAmerican ethnicity, lack of maternal prenatal vitD intake and winter birth were predictive of low vitD status at birth in EPTIs. Since EPTIs are usually hospitalised after birth, vitD synthesis from sunlight exposure is lacking. Thus, repletion of vitD status during hospitalisation depends entirely on exogenous sources. There are limited recent reports on vitD intake in preterm infants during birth hospitalisation. ${ }^{9}{ }^{10}$ Our study demonstrated that although total daily vitD intake from all sources increased progressively with age (data not shown), only $60 \%$ of this cohort of infants achieved an intake of $400 \mathrm{IU} /$ day of vitD by 36 weeks PMA or at discharge. During hospitalisation, low vitD status at birth and suboptimal vitD intake appear to militate against the achievement of serum 25(OH)D concentrations $\geq 50 \mathrm{nmol} / \mathrm{L}$ in many preterm infants. Although professional bodies $^{1}{ }^{3} 4$ recommend $25(\mathrm{OH}) \mathrm{D}$ concentrations $>50 \mathrm{nmol} / \mathrm{L}$ to promote bone health, the effect of target serum $25(\mathrm{OH}) \mathrm{D}$ concentration on clinical outcomes in infants is lacking and merits evaluation.

Our study had several strengths. To our knowledge, it is the first reported multicentre investigation of vitD status in infants born $<32$ weeks gestation and monitored longitudinally from birth until hospital discharge. It provides data on the vitD status achieved by EPTIs born $<32$ weeks PMA based on conventional nutritional practices in the NICU settings. Thus, our results are likely generalisable to infants in NICUs and will inform future intervention trials to assess the effect of optimising vitD status in preterm infants on short- and long-term clinical outcomes.

\section{CONCLUSIONS}

In this study, neither the vitD intake, nor the recommended serum $25(\mathrm{OH}) \mathrm{D}$ concentrations of $\geq 50 \mathrm{nmol} / \mathrm{L}$ were attained in many EPTIs. The serum $25(\mathrm{OH}) \mathrm{D}$ concentrations of infants were directly correlated with maternal vitD status at birth. Therefore, vitD status should be optimised in pregnant women as part of strategy to replete the offspring. In addition, EPTIs require heightened attention to vitD supplementation in the NICU to improve vitD intake and vitD status. In view of potential putative roles for vitD in several biologic functions, studies are needed to test the effect of targeting serum $25(\mathrm{OH}) \mathrm{D}$ concentrations of $\geq 50 \mathrm{nmol} / \mathrm{L}$ on clinically relevant health outcomes.
Acknowledgements We thank the research nurses and staff of the Ohio Perinatal Research Network (OPRN) and the staff at the University of Cincinnati Medical Center NICU for assistance in collecting study samples.

Contributors NM obtained Institutional Review/Ethical Board approval at University of Cincinnati Medical Center, enrolled subjects at the Cincinnati centre, extracted data from the electronic medical records, collated data on serum 25-hydroxyvitamin-D concentrations and wrote the first draft of the manuscript; JLS obtained Institutional Review/Ethical Board approval at the Columbus centres, enrolled subjects in Columbus, Ohio, collated and analysed the demographic and serum 25-hydroxyvitamin-D data, and contributed to several revisions of the manuscript; CS collated data on dietary intake of vitamin D and contributed to the Methods section of the manuscript; AD developed the concept for the study, supervised the conduct of the study and contributed to the revisions resulting in the final version of the manuscript; HTA developed the concept for the study, supervised the management of the data, supervised the conduct of the study and contributed to the later versions of the manuscript.

\section{Competing interests None.}

Ethics approval University of Cincinnati, Ohio and Nationwide Children's Hospital, Columbus, Ohio (Note: Nationwide Children's Hospital and The Ohio State University have a reciprocity agreement in place. Approval by the Nationwide IRB permits investigations at both institutions).

Provenance and peer review Not commissioned; externally peer reviewed.

Data sharing statement The manuscript data, the nutrition data and anthropometric data will be made available to all investigators upon request.

Open Access This is an Open Access article distributed in accordance with the Creative Commons Attribution Non Commercial (CC BY-NC 3.0) license, which permits others to distribute, remix, adapt, build upon this work non-commercially, and license their derivative works on different terms, provided the original work is properly cited and the use is non-commercial. See: http://creativecommons.org/ licenses/by-nc/3.0/

\section{REFERENCES}

1 Wagner $\mathrm{CL}$, Greer FR. Prevention of rickets and vitamin D deficiency in infants, children, and adolescents. Pediatrics 2008;122:1142-52.

2 Camargo CA Jr, Ingham T, Wickens K, et al. Cord-Blood 25-Hydroxyvitamin D Levels and Risk of Respiratory Infection, Wheezing, and Asthma. Pediatrics 2011;127:e180-7.

3 Institute of Medicine. Dietary reference intakes for calcium and vitamin D. Washington, DC: The National Academies Press, 2011.

4 Agostoni C, Buonocore G, Carnielli VP, et al. Enteral nutrient supply for preterm infants: commentary from the European Society of Paediatric Gastroenterology, Hepatology and Nutrition Committee on Nutrition. J Pediatr Gastroenterol Nutr 2010;50:85-91.

5 Dawodu A, Nath R. High prevalence of moderately severe vitamin D deficiency in preterm infants. Pediatr Int 2011;53:207-10.

6 Hollis BW, Roos BA, Draper HH, et al. Vitamin D and its metabolites in human and bovine milk. J Nutr 1981;111:1240-8.

7 Bodnar LM, Simhan HN, Powers RW, et al. High prevalence of vitamin D insufficiency in black and white pregnant women residing in the northern United States and their neonates. J Nutr 2007;137:447-52.

8 Hollis BW, Wagner CL. Assessment of dietary vitamin D requirements during pregnancy and lactation. Am J Clin Nutr 2004;79:717-26.

9 McCarthy RA, McKenna MJ, Oyefeso O, et al. Vitamin D nutritional status in preterm infants and response to supplementation. Br J Nutr 2012:1-8.

10 Taylor SN, Wagner CL, Fanning D, et al. Vitamin D status as related to race and feeding type in preterm infants. Breastfeed Med 2006;1:156-63. 